\section{Competing responses at the goal as a function of percent reinforcement, amount of reinforcement, and deprivation condition}

\author{
ELVIS C. JONES \\ Frostburg State College, Frostburg, Md. 21532
}

Competing responses emitted after Ss reached the foodcup were observed in a straight runway as a function of $100 \%$ or $50 \%$ reinforcement, 1 - or 20 -pellet rewards, and 6 or $21 \frac{1 / 2}{h}$ of deprivation. During acquisition and extinction, large rewards increased postgoal competing responses, but higher deprivation suppressed these responses. Partially reinforced Ss produced more postgoal competing responses during extinction than did consistently reinforced Ss. When Ss were trained on a 50\% schedule, postgoal competing responses were positively related to runway performance. This relationship was negative for Ss trained on a $100 \%$ schedule.

Competing responses have played a role in a variety of theories (e.g. Amsel, 1958, 1962; Estes, 1959; Weinstock, 1954, 1958; Hulse \& Stanley, 1956). Although these theories have focused upon behavior in runways, they have considered competing responses emitted after the $S$ reaches the empty foodcup to be prototypes for competing responses in the runway proper. As postgoal competing responses develop or diminish, competing responses in the runway are assumed to follow suit. Direct evidence supporting this relationship has been obtained (Jones, 1970).

It appears worthwhile to determine if variables that affect runway performance also affect postgoal competing responses in a consistent manner. The runway variables that have been of greatest experimental interest have included percent reinforcement (e.g., McCoy \& Marx, 1965; Jones \& Bridges, 1966; Harris, Smith, \& Weinstock, 1962; Kirkpatrick, Pavlik, \& Reynolds, 1964 Bradley \& Wong, 1969), amount of reinforcement (e.g., Pereboom \& Crawford, 1958; Smoot, 1963; Kirkpatrick, 1964; Kintch, 1962; Marx \& Browstein, 1963), and deprivation condition (e.g., Cotton, 1953; King, 1959; Cicala, 1961; Mikulka \& Pavlik, 1966; Jones \& Bridges, 1967; Champion, 1967; Porter, Madison, \& Senkowski, 1968; Bindra, 1963).

Competing responses in goalboxes have been studied as a function of these variables (e.g., Goodrich, 1959; McCoy \& Marx, 1965; Theios \& Polson, 1962; Brown \& Logan, 1965; Longstreth, 1964). However, in some of these experiments, competing responses produced by partially reinforced Ss on rewarded trials were not distinguished from those that occurred on nonrewarded trials. In addition, some of these experiments failed to distinguish between competing responses that occur before Ss reach the goal cup and competing responses that occur after they reach the cup.

In evaluating competing response theories, these distinctions are crucial. For example, Hulse \& Stanley (1965) assume that partially reinforced Ss learn to stay at the foodcup (eating) the foodcup on nonrewarded trials and engage in other behavior. In contrast, Weinstock's theory (Weinstock, 1954) leads to an opposite prediction. According to Weinstock, partially reinforced $S s$ learn to stay at the foodcup even on nonrewarded trials.

The postgoal competing response measure employed in the present experiment was the time spent at the foodcup prior to turning away. Jones (1970) found this to be a reliable measure which was correlated with competing responses in the runway. Furthermore, this response should be a sensitive measure that could be used in testing the theories of Amsel (1958, 1962), Hulse \& Stanley (1956), and others.

\section{SUBJECTS}

Eighty male Sprague-Dawley rats, 100 days old at the start of the experiment, served as Ss.

\section{APPARATUS}

The apparatus was a straight runway consisting of a 12-in. startbox, 24-in. runway, and a 12-in. goalbox. The apparatus was 3 in. wide and 6 in. high throughout. The apparatus was painted flat gray throughout and was covered by frosted Plexiglas. A stainless steel foodcup, $1 \frac{1 / 4}{4}$ in. in diam and $1 / 2$ in. deep, was bolted to the floor, 1 in. from the end of the goalbox. on rewarded trials, but to turn from
Raising the startbox door activated a Standard timer. The timer was stopped when the $S$ broke a photobeam located $t \mathrm{in}$, inside the goalbox. Another photobeam was positioned $1 \frac{1 / 2}{\mathrm{in}}$. in front of the foodcup. An event marker on an Esterline Angus event recorder was activated when this photobeam was broken and continued to be activated until the photobeam was no longer broken.

The Ss were randomly assigned to the eight cells of a 2 by 2 by 2 factorial design with $10 \mathrm{Ss}$ per cell. The factors and levels were as follows: percent reinforcement $(100 \%, 50 \%)$, amount of reinforcement ( 1 pellet, 20 pellets), and deprivation condition $(6 \mathrm{~h}, 211 / 2 \mathrm{~h})$.

$\mathrm{Ss}$ in the $50 \%$ groups were reinforced on a random schedule, with the provision that no more than three successive trials would be reinforced or nonreinforced. The trials on which reinforcement occurred were determined separately for each $S$ in the $50 \%$ groups. However, all Ss were reinforced on the first and last acquisition trials.

All Ss were placed on a $23 \cdot \mathrm{h}$ food-deprivation schedule for 14 days prior to the start of the experiment. Water was available in the home cages at all times. Ss in the 6-h groups had all food withdrawn from their home cages $6 \mathrm{~h}$ prior to each experimental session. The other $S s$ had all food withdrawn from their home cages $21 \frac{1}{2} \mathrm{~h}$ prior to each experimental session. All Ss were allowed to eat for $1 \mathrm{~h}$ each day, beginning $23 \mathrm{~h}$ after they were placed on their deprivation period. Regardless of deprivation schedule, all Ss were run at the same time each day.

Ss in the 1-pellet groups received 1 Noyes 45-mg pellet on each reinforced trial, and the other $S s$ received 20 of these pellets on each reinforced trial. During the regular feeding period each day, the $S s$ received as many Noyes 45-mg pellets as required to bring their daily intake of these pellets to 20 .

Each $\mathrm{S}$ was given 32 acquisition trials and 16 extinction trials beginning on the day following the last acquisition trial. All Ss received their acquisition and extinction trials at the rate of one trial per day. The order in which the Si were to be run was determined randomly prior to each trial.

On all rewarded trials, the Ss were removed from the goalbox as soon as they finished eating or after $30 \mathrm{sec}$, whichever occurred later. On nonreinforced trials, the Ss were removed from the goalbox after $30 \mathrm{sec}$. During extinction a $30-\mathrm{sec}$ goalbox confinement period was used 


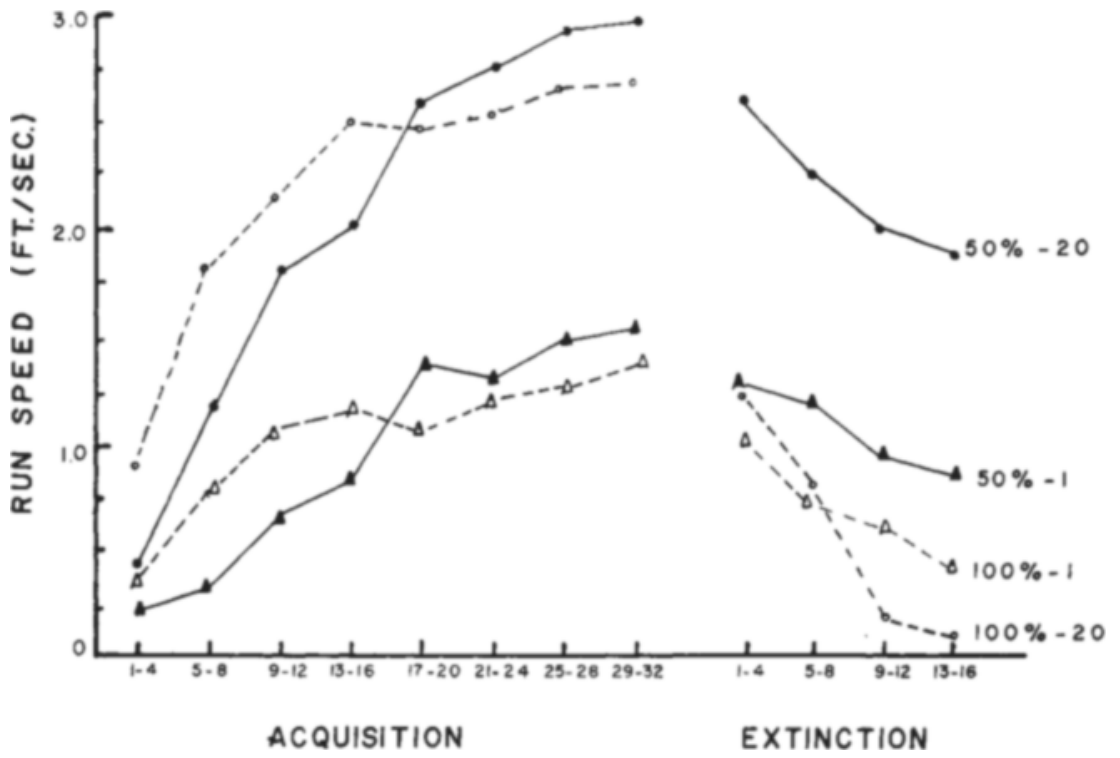

Fig. 1. Mean running speeds of Ss trained on $100 \%$ or $50 \%$ reinforcement and receiving either 1 - or 20 -pellet reinforcements.

on all trials. The entire apparatus was washed and dried with sponges after each $\mathrm{S}$ completed each trial.

$$
\text { RESULTS }
$$

\section{Running Speeds}

Although running speeds were not of direct interest in the study, they are briefly reported here. As shown in Fig. 1, running speeds during acquisition and extinction paralleled typical findings. The only significant interaction was between percent and amount of reinforcement. Therefore, Fig. 1 is based on data averaged over deprivation levels.

There was an initial superiority on the part of consistently reinforced Ss. Comparing the mean running speeds of the $100 \%$ and $50 \% \mathrm{Ss}$ on the first block of four trials, $t=1.98, \mathrm{df}=78$, $\mathrm{p}<.05$. However, the $50 \%$ Ss eventually achieved faster speeds. Comparing the mean running speeds of the $100 \%$ and $50 \%$ Ss on the final block of four trials, $t=2.63$, $d f=78$, $\mathrm{p}<.005$. During extinction a clear partial-reinforcement effect was obtained (main effect of percent reinforcement, $\mathrm{F}=10.86, \mathrm{df}=1 / 72$, $\mathrm{p}<.005$ ). Ss deprived for $21 \frac{1 / 2}{h} \mathrm{ran}$

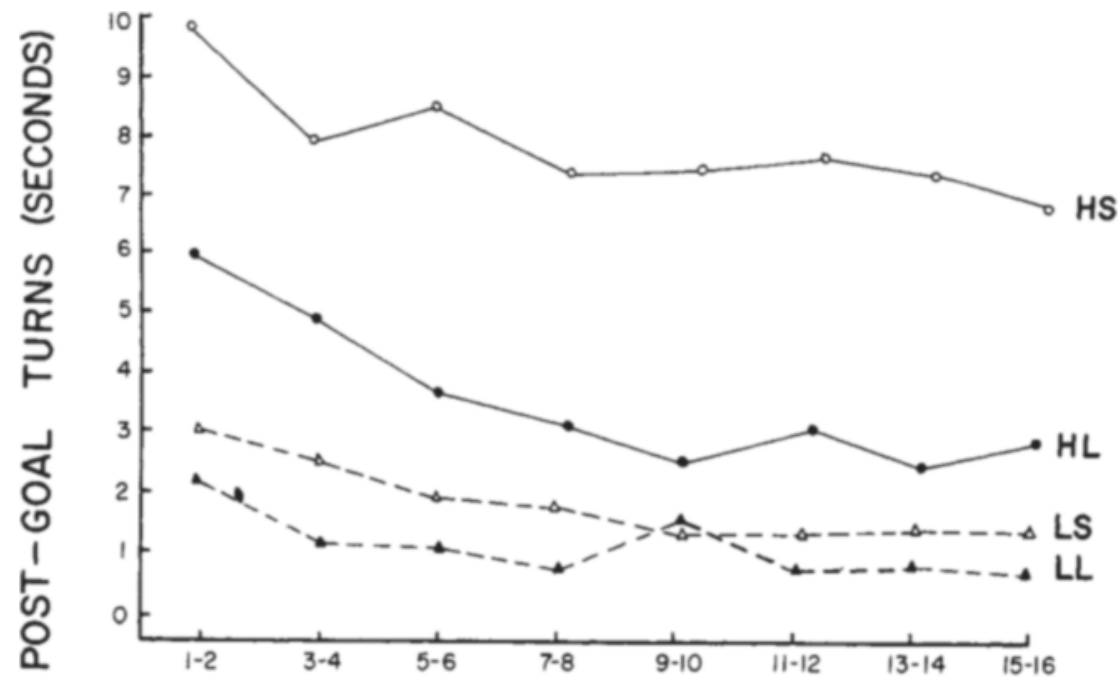

\section{EXTINCTION TRIALS}

Fig. 2. Mean latencies of initially turning from the empty foodcup during extinction as a function of deprivation state $\left(H=21^{1 / 2} \mathrm{~h}, \mathrm{~L}=6 \mathrm{~h}\right)$ and amount of reinforcement ( $S=1$ pellet, $L=20$ pellets $)$. Partially reinforced and consistently reinforced groups are combined. faster than did Ss deprived only $6 \mathrm{~h}$ during both acquisition ( $\mathrm{F}=4.71$, $\mathrm{d} \mathbf{f}=1 / 72, \quad \mathbf{p}<.05)$ and extinction $(F=4.84, \quad$ df $=1 / 72, \quad p<.05)$. Ss reinforced with 20 pellets ran faster during acquisition than did Ss reinforced with only 1 pellet $(F=5.08$, df $=1 / 72, p<.05)$. During extinction, however, large reinforcements enhanced the performance of $50 \%$ groups but depressed the performance of $100 \%$ groups (Percent Reinforcement by Amount Reinforcement interaction, $F=8.87, \mathrm{df}=1 / 72, \mathrm{p}<.005)$.

\section{Competing Responses}

During Acquisition

During acquisition the postgoal competing-response measure was meaningful only for the $50 \%$ Ss, since the $100 \%$ Ss never encountered an empty foodcup during acquisition.

The effect of increased deprivation was to keep Ss at the cup, but the effect of large reinforcements was to increase the Ss' tendency to turn rapidly from the empty cup. The main effect of deprivation was significant $(\mathrm{F}=9.41, \quad \mathrm{df}=1 / 36, \quad \mathrm{p}<.05)$. The interaction between deprivation and amount of reinforcement was also significant $(F=7.20, \quad d f=1 / 36$, $\mathbf{p}<.025)$. There was a slight decrease in turn latencies as acquisition continued. However, the trials main effect was not significant $(.15>p>.10)$, nor was the Groups by Trials interaction $(.20>\mathrm{p}>.15)$.

\section{Competing Responses}

During Extinction

As indicated by Fig. 2, during extinction the $50 \%$ groups turned from the empty foodcup more rapidly than did their $100 \%$ counterparts. This difference was significant $(F=4.05$, df $=1 / 72, p<.05)$. There were no significant interactions between percent of reinforcement and either of the other variables. Furthermore, a repeated-measure trend analysis (Edwards, 1960) indicated that the $50 \%$ and the $100 \%$ reinforced groups had almost identical trends during extinction (Percent by Trials interaction, $F=1.0006$ ). Therefore, Fig. 3 combines the partially and consistently reinforced groups.

The effects of deprivation and amount of reinforcement were generally the same during extinction as in acquisition. The main effect of deprivation was significant $(F=8.85$, $\mathrm{df}=1 / 72, \mathrm{p}<.005$ ), as was the main effect of amount of reinforcement $(\mathrm{F}=4.68, \mathrm{df}=1 / 72, \quad \mathrm{p}<.05)$. The interaction between amount of reinforcement and deprivation was significant $(\mathrm{F}=6.19, \quad \mathrm{df}=1 / 72$, $\mathrm{p}<.025$ ). All groups had a tendency to decrease their turning latencies as extinction continued (main effect of 
trials, $\quad F=5.84, \quad d f=15 / 1080$, $p<.005)$. However, the Groups by Trials interaction was not significant $(.15>p>.10)$.

\section{DISCUSSION}

The data indicate that variables that affect runway performance also affect postgoal behavior. Specifically, the data suggest three principal conclusions: (1) Contrary to Weinstock's (1954) theory, partially reinforced $S$ s do not learn to remain at the goal cup on nonreinforced acquisition trials. Rather, as predicted by Hulse \& Stanley (1956) partial reinforcement reduces postgoal turn latencies. (2) The effect of deprivation is to increase postgoal turn latencies, and (3) the effect of large amounts of reinforcement is to decrease postgoal turn latencies.

The opposite effects of amount of reinforcement and deprivation are not as enigmatic as may at first appear. The Ss were motivated to reduce their deprivation and they could do so only by approaching and by eating from the foodcup. Reinforcement, on the other hand, presumably resulted in frustration when the Ss later found the foodcup empty. Frustration is assumed to be an aversive drive state, and $S$ s will be motivated to reduce frustration. Since the Ss were confined in the goalbox, the only way they could reduce frustration was to avoid attending to cues that were previously associated with reinforcement (especially the foodcup). Since large reinforcements should result in greater frustration, $S$ s that received large reinforcements should be more motivated to turn rapidly from the empty foodcup.

Extending this viewpoint, competing responses can be considered instances of operant behavior transformed into discriminated operants when $S s$ are trained on a partial-reinforcement schedule. The tendency to emit pregoal competing responses tends to weaken (possibly because these responses delay reinforcement), but postgoal competing responses continue to occur because they serve to reduce frustration. The result is that when postgoal competing responses are increased during extinction, they will not be readily generalized from the goalbox to the runway. A similar hypothesis could be derived from Allison, Peterson, \& Andry (1970). ${ }^{1}$

Provided that the $\mathrm{S}$ has learned to discriminate between pre- and postgoal events, most motivational variables should enhance performance during extinction. However, if the $\mathrm{S}$ has not learned this discrimination, then a motivational variable will enhance performance during extinction if the motive is satisfied by goal approach (e.g., as is the case with deprivation) but will decrease resistance to extinction if the motive is satisfied by behavior that competes with goal approach (e.g., as is the case with frustration resulting from nonreinforcement).

\section{REFERENCES}

ALLISON, J. Time spent in the goal box Effects of frequency and schedule of reinforcement. Psychonomic Science, 1967, 7, 165-166.

ALLISON, J., PETERSON, G., \& ANDRY, $M$. Retrace effect in rats' extinction performance following discrimination training and training with differential reward magnitude. Journal of Comparative \& Physiological Psychology, 1970, 70, 308-316.

AMSEL, A. The role of frustrative nonreward in non-continuous reward situations. Psychological Bulletin, 1958, $55,102-119$

AMSEL, A. Frustrative nonreward in partial reinforcement and discrimination learning: Some recent history and a theoretical extension. Psychological Review, 1962, 69, 306-328.

BINDRA, D. Effects of nonreinforcement, drive-diminution, and punishment on relevant and irrelevant behavior in the runway. Psychological Record. 1963, 13. 253-282.

BRADLEY, H. W. \& WONG, R. Extinction as a function of size of goal box. reinforcement schedule, and competing responses. Psychonomic Science, 1969 17, 189-191.

BROWN, R. T. \& LOGAN, F. A Generalized partial reinforcement effect. Journal of Comparative \& Physiological Psychology, 1965, 60, 64-69.

CHAMPION, R. A. Effect of competing responses as a function of deprivation time. Journal of Experimental Psychology, 1967, 73, 503-508.

CICALA, G. A. Running speed in rats as a function of drive level and presence or absence of competing response trials. Journal of Experimental Psychology, $1961,62,329-334$

COTTON. J. W. Running time as a function of amount of food deprivation. Journal of Experimental Psychology, 1953,46, 341-357.

EDWARDS, A. Experimental design in psy chological research. New York: Holt, Rinehart, \& Winston, 1960

ESTES, W. K. The statistical approach to learning theory. In S. Koch (Ed.), Psychology: A study of a science. Vol. 2 . New York: MeGraw-Hill, 1959. Pp. 380-491.

GOODRICH, $\dot{\mathrm{K}}$. P. Performance in different segments of an instrumental response chain as a function of reinforcement schedule. Journal of Experimental Psychology, 1959, 57, 57-63.

HARRIS, S. J., SMITH, M. G., \& WEINSTOCK, S. Effects of nonreinforcement on subsequent reinforced running behavior. Journal of Experimental Psychology, 1962, 64, 388-392.

HULSE, S. H., JR., \& STANLEY, W. C. Extinction by omission of food as related to partial and secondary reinforcement. Journal of Experimental Psychology, $1956,52,221-227$.
JONES, E. C, A correlational study of preand post-goal competing responses. Psychonomic Science, 1970,21, 25-27. JONES, E. C., \& BRIDGES, C. C.. JR Competing responses and the partial reinforcement effect. Psychonomic Science, $1966,6,483-484$

JONES, E. C., \& BRIDGES. C. C., JR. The partial reinforcement effect and competing behavior in a latent learning situation. Psychonomic Science, 1967, 7. 119-120.

KING, R. A. The effects of training and motivation on the components of a learned instrumental response. Unpublished doctoral dissertation, Duke University, 1959

KINTSCH, W. Runway performance as a function of drive strength and magnitude of reinforcement. Journal of Comparative \& Physiological Psychology, 1962, 55 882-887.

KIRKPATRICK, D. R. The effects of amount and percentage of reinforcement and goal box size on conditioning and extinction. Dissertation Abstracts, 1964 25 (Part 2), 2069.

KIRKPATRICK, D. R.. PAVLIK, W. B.. \& REYNOLDS. W. F. Partial reinforcement extinction effect as a function of the size of the goal box. Journal of Experimental Psychology, 1964,68, 515-516.

LONGSTRETH, L. E. Partial re inforcement effect and extinction as a function of frustration and interfering responses. Journal of Experimental Psychology. $1964,67,581-586$.

MARX, M. H., \& BROWSTEIN, A. J Effects of incentive magnitude on running speeds without competing responses in acquisition and extinction. Journal of Experimental Psychology, $1963,65,182-189$

McCOY, D. F., \& MARX, M. H. Competing responses and the partial reinforcement effect. Journal of Experimental Psychology, 1965, 70, 35 2-356.

MIKULKA, P. J., \& PAVLIK, W. B. Deprivation level, competing responses, and the PRE. Psychological Reports, $1966,18,95-102$.

PEREBOOM, A. C., \& CRAWFORD, B. M Instrumental and competing behavior as a function of trials and reward magnitude. Journal of Experimental Psychology, $1958,56,82-85$.

PORTER, J. J., MADISON, H. L., \& SENKOWSKI, P. C. Runway performance and competing responses as functions of drive level and method of drive measurement. Journal of Experimenta Psychology, 1968, 78, 281-284.

SMOOT, K. E. Effects of drive strength and incentive magnitude with and without competing responses. Dissertation Abstracts, 1963, 24 (Part 4), 3442.

THEIOS, J., \& POLSON, P. Instrumental and goal responses in nonresponse partial reinforcement. Journal of Comparative \& Physiological Psychology, 1962, 55 , 987.991 .

WEINSTOCK, S. Resistance to extinction of a running response following partia reinforcement under widely spaced trials. Journal of Comparative \& Physiologica Psychology, 1954, 47, 318-322.

WEINSTOCK, $S$ Acquisition and extinction of a partially reinforced running response at a 24-hour intertrial interval. Journal of Experimental Psychology, 1958, 56 , 151-158.

\section{NOTE}

1. It should be noted that the present data may be at odds with the results reported by Allison (1967), Allison, Peterson, \& Andry (1970). This is difficult to judge because of the many ways in which their studies differ from the present study. 